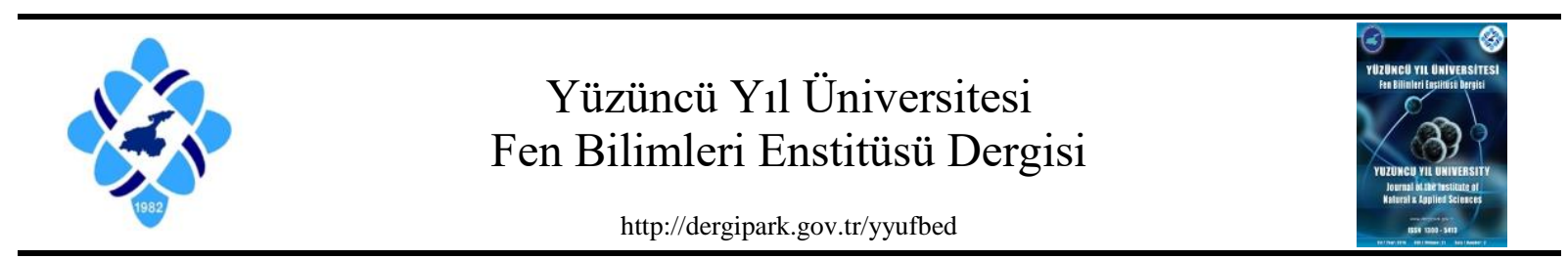

Araştırma Makalesi

\title{
Alzheimer Hastalığı Tedavisinde Etkili Cyclo(Phe-Phe) Dipeptidinin Konformasyon Analizi
}

\author{
Sefa ÇELİK ${ }^{* 1}$, Sevim AKYÜZ ${ }^{2}$, Ayşen ERBÖLÜKBAŞ ÖZEL ${ }^{1}$ \\ ${ }^{1}$ İstanbul Üniversitesi, Fen Fakültesi, Fizik Bölümü, 34134, İstanbul, Türkiye \\ 2 İstanbul Kültür Üniversitesi, Fen-Edebiyat Fakültesi, Fizik Bölümü, 34156, İstanbul, Türkiye
Sefa ÇELIK, ORCID No: 0000-0001-6216-1297, Sevim AKYÜZ, ORCID No: 0000-0003-3313-6927, Ayşen ERBÖLÜKBAŞ ÖZEL, ORCID No: 0000-0002-8680-8830
*Sorumlu yazar e-posta: scelik@istanbul.edu.tr

\section{Makale Bilgileri \\ Geliş: 23.05.2021 \\ Kabul: 03.07.2021 \\ Online Aralık 2021 \\ DOI: $10.53433 /$ yyufbed.941445}

\section{Anahtar Kelimeler}

Cyclo(Phe-Phe),

Dipeptit,

Konformasyon Analizi,

Moleküler Modelleme
Öz: Cyclo(Phe-Phe) dipeptidi Alzheimer hastalığı tedavisinde etkili bir dipeptitdir. Bu çalışmada Cyclo(Phe-Phe) dipeptidinin 3-Boyutlu yapısı teorik konformasyon analizi (TKA) metodu ile belirlenmiştir. Konformasyon analizinde, Ramachandran haritalarından yararlanılarak ve yan-zincir dihedral açıları $(\chi)$ yardımıyla tüm olası konformasyonlar belirlenmiştir. $\mathrm{Bu}$ haritalar kullanılarak programa girilen başlangıç dihedral açılarla, konformasyon analizi sonunda hesaplanan dihedral açılar karşılaştırmalı olarak verilerek tablolaştırılmışıtır. Hesaplama sonucunda dipeptidin en kararlı beş konformasyonunun toplam enerjileri ve toplam enerjilerine katkı sağlayan van der Waals, elektrostatik, hidrojen bağ ve torsiyon enerjileri ayrı ayrı hesaplanmıştır. Ek olarak, en minimum enerjili konformasyon Gaussian03 programı ile DFT metodu kullanılarak optimize edilmiștir. Belirlenen optimize geometri ile konformasyon analizi sonrasında elde edilen geometri karşılaş̧ırılmıştır.

\section{Conformational Analysis of Cyclo (Phe-Phe) Dipeptide Effective in the Treatment of Alzheimer's Disease}

\section{Article Info}

Recieved: 23.05.2021

Accepted: 03.07.2021

Online December 2021

DOI: $10.53433 /$ yyufbed.941445

\section{Keywords}

Cyclo(Phe-Phe),

Dipeptide,

Conformational analysis,

Molecular modeling

\begin{abstract}
Cyclo (Phe-Phe) dipeptide is an effective dipeptide in the treatment of Alzheimer's disease. In this study, the 3-dimensional structure of the Cyclo (PhePhe) dipeptide was determined using the theoretical conformation analysis method. All possible conformations were calculated by conformation analysis, using Ramachandran maps and with the aid of side-chain dihedral angles $(\chi)$. By using these maps, the initial dihedral angles entered into the program and the dihedral angles calculated as a result of conformational analysis are given comparatively and tabulated. As a result of the calculation, the total energies of the five most stable conformations of the dipeptide and van der Waals, electrostatic, hydrogen and torsion energies contributing to the total energies were calculated separately. In addition, the lowest energy conformation was optimized by using DFT method with Gaussian 03 program. The determined optimized geometry was compared with the geometry obtained after conformational analysis.
\end{abstract}




\section{Giriş}

Amino asitlerden türetilen 2-5-Diketopiperazinler (DKP) ayrıca çeşitli gıda ve organizmalarda bulunan bileşiklerin bir sınıfıdır (Kelley ve ark., 2017). Lineer amino asitlerden yapısal olarak daha kararlı olmaları nedeniyle DKP içeren materyaller çok daha gelişmiş özelliklere sahip olabilmektedir (Gao, 2013). Ayrıca biyo-uyumlulukları sayesinde DKP' ler, ilaç taşıma ve diğer tıbbi amaçlar için farmakoloji endüstrisinde başarıyla kullanılmıştır (Kelley ve ark., 2017; Gao, 2013; Sun ve ark., 2017; Gellerman ve ark., 2008; Zhang \& Wang, 2018). DKP' lerin çeşitli yiyeceklerin tadına katkıda bulunabilecek bir dizi kimyasal etki sergilediği bulunmuştur. Bu en küçük halka peptidler, antibakteriyel ve antifungal etkilere kadar çeşitli biyoaktiviteler sergiledikleri ve yeni fonksiyonel gıdaların geliştirilmesinde kullanılma potansiyeline sahip oldukları bulunmuştur (Borthwick \& Da Costa, 2017). Kaur ve ark. (2020) tarafından bazı doğrusal ve halka peptitler üzerine antienflamatuar aktivite çalışmaları yapılmıştır. Analiz sonucunda incelenen halka peptitlerin, doğrusal peptitlere göre daha yüksek antienflamatuar aktivite gösterdiği bulunmuştur. Yüksek kararlılık, düşük sentez maliyeti, düşük toksisite ve yüksek aktivite, yeni ilaçlar tasarlamak ve geliştirmek için halka peptitleri daha çekici hale getirmektedir. Mikroorganizmalara karşı yüksek özgüllük ve ökaryotik hücreler için minimum toksisiteye sahip halka antimikrobiyal peptidleri tasarlamak mümkündür. Yapılacak çalışmalar antibiyotiğe dirençli enfeksiyonlarla savaşmaya yardımcı olacak yeni ilaçların geliştirilmesine sağlayacaktır (Falanga ve ark., 2017). Doğal kaynaklardan izole edilen halka peptitler, çok çeşitli biyolojik profiller göstermektedir. Bu peptitler, özel uzaysal veya konformasyonel yapıları ve çeşitli amino asitleri içermesi nedeniyle biyokimyasal etkileşimleri incelemek için önemli ilaç adaylarıdır. $\mathrm{Bu}$ moleküllerin biyolojik yeterliliği, kanser, bakteriyel, mantar ve viral hastalıklar gibi çeşitli tıbbi hastalıkları kapsamaktadır (Rahman, 2019). Cyclo(phe-phe) dipeptidi üzerine yapılan bir çalışmada antelmintik aktiviteye sahip olduğu raporlanmıştır (Walchshofer ve ark., 1997).

Yapılan hayvan testlerinde, tavuk özlü bazı gıdalarda bol miktarda bulunan cyclo(phe-phe)' in depresyonun başlangıcını ortadan kaldırabildiği ve böylece Alzheimer hastalığının gelişimini önlemeye katkıda bulunabileceği gösterilmiştir (Tsuruoka ve ark., 2012). HT-29 and Caco-2 hücre kültürleri üzerine yapılan çalışmada Cyclo(phe-phe) dipeptidinin karsinomun büyümesini engellediği ve bu nedenle kanser tedavisi sunan bir ajan olarak kullanılabileceği raporlanmıştır (Graz ve ark., 2000).

Cyclo(phe-phe) dipeptidinin sahip olduğu bu aktiviteleri açıklayabilmek için yapı-aktivite ilişkisi kapsamında bu dipeptidin aktivite gösterdiği en düşük enerjili konformasyonun belirlenmesi kilit öneme sahiptir. En olası konformasyonlar, aminoasitlerin $\varphi, \psi$ ve $\chi$ dihedral açıları ile belirlenen Ramachandran haritalarından (Mills ve ark., 1988) yararlanarak moleküler mekanik yaklaşıma dayalı hesaplama yapan teorik konformasyon analizi programıla belirlenmiştir.

Konformasyon analizi sonrasında cyclo(phe-phe) dipeptidinin olası en kararlı beş konformasyonu belirlenmiştir. Bu beş konformere ait moleküler geometri, fenilalanin aminoasitinin yan zincirine ait dihedral açıdaki değişim ve her konformerin enerjisi Maksumov vd. tarafından yazılan teorik konformasyon analizi programı kullanılarak hesaplanmıştır (Maksumov ve ark., 1983). Ayrıca toplam enerjiye katkı sağlayan van der Waals, elektrostatik ve torsiyon enerjileri hesaplanmıştır. Cyclo(Phe-Phe) dipeptidi, kuantum kimyasal ab-initio hesaplama ile optimize edilmiştir. Optimize geometri, konformasyon analizi ile bulunan geometri ile karşılaştırılmıştır.

\section{Materyal ve Yöntem}

Teorik konformasyon analizi (TKA) hesaplamaları van der Waals etkileşimleri, elektrostatik etkileşimleri, hidrojen bağları ve tekli bağlar etrafında sınırlı dönü hareketlerini kapsamaktadır. İlk terim Scott ve Scheraga tarafindan belirlenen parametrelerle Lennard-Jones 6-12 potansiyeli ile tanımlanmıştır (Popov, 1985).

Elektrostatik enerji, Scott ve Scheraga tarafından önerilen kısmi yükler ile Coulomb yasasına karşı1ık gelen monopol yaklaşımla hesaplanmıştır (Popov, 1985). Momany ve arkadaşları tarafından verilen iç rotasyon bariyerlerinin değeri kullanılarak torsiyon enerjisi hesaplanmıştır (Mills ve ark., 1988).

Hidrojen bağ enerjisi, Morse potansiyeline dayalı olarak hesaplanmıştır. Bağ uzunlukları ve açılar için Corey ve Pauling tarafindan belirlenen değerler kullanılmıştır ve sabit tutulmuştur (Popov, 1979). 
Dihedral dönü açıları IUPAC-IUB' a göre belirlenmiştir (Mills ve ark., 1988). Toplam enerji, Maksumov ve ark. (1983) tarafindan yazılan program kullanılarak hesaplanmıştır. Konformasyon analizi ile $\chi$ yan zincir dihedral açılarına bağlı olarak olası kararlı beş konformasyon belirlenmiştir. Belirlenen en düşük enerjili konformer Gaussian03 programı (Frisch ve ark., 2003), DFT metodu (Becke, 1993), B3LYP fonksiyoneli ve 6-31++G(d,p) baz seti kullanilarak optimize edilerek mulliken yükleri hesaplanmıştır. Ayrıca optimize geometri ile en düşük enerjili konformasyon karşılaştırılmıştır.

\section{Bulgular}

Diketopiperazinin (DKP) kristal yapısı üzerine yapılan çalışmalarda halka yapının düzlemsel olduğu belirlenmiştir (Corey, 1938; Degeilh \& Marsh, 1959; Dorset, 2010). Bu nedenle çalışma da cyclo(phe-phe) dipeptidine ait halka yapının düzlemsel olduğu varsayılmıştır ve konformasyonların toplam enerjisi $\chi 11, \chi 12, \chi 21$ ve $\chi 22$ dihedral açılarına bağlı olarak hesaplanmıştır.

Beş konformasyona ait konformasyon analizi öncesi ve sonrası dihedral açıları, toplam enerjileri ve van der Waals, elektrostatik, torsiyon enerji katkıları Çizelge 1 ve 2' de gösterilmiştir. Kararlı beş konformasyona ait moleküler geometriler Şekil 1 de verilmiştir. DFT/B3LYP/6-31++G(d,p) teori seviyesinde dipeptide ait optimize geometri, $\chi 11, \chi 12, \chi^{21}$ ve $\chi 22$ dihedral açılarının gösterimi ve yük dağılımları Şekil 2 ve Şekil 3' de gösterilmiştir. Konformasyon analizi ve optimizasyon sonrası yan zincir dihedral açılarındaki değişim Çizelge 3' de verilmiştir.

Cyclo(phe-phe) dipeptidinin konformasyon analizi sonucunda belirlenen en kararlı beş konformasyona ait toplam enerjiler sırasıyla $-6.56,-4.77,-3.99,-2.45$ ve $-0.90 \mathrm{kcal} / \mathrm{mol}$ hesaplanmıştır. $\mathrm{Bu}$ beş konformasyonda toplam enerjiye olan en yüksek katkının van der Waals enerjisinden olduğu bulunmuştur. Literatürde peptitler üzerine yapılan çalışmalarla bu sonuç son derece uyumludur (Demir \& Godjaev, 2002; Alieva ve ark., 2006; Celik \& Kecel-Gunduz, 2017). En kararlı konformasyona (I) van der Waals enerjisinden olan katk1 $-6.49 \mathrm{kcal} / \mathrm{mol}$ ' dür. TKA ve DFT/B3LYP/6-31++G(d,p) teori seviyesi kullanılarak belirlenen konformasyonlar incelendiğinde (Şekil 4), fenilalanin amino asitine ait halka kısımlarının birbirlerine yaklaştığı ve katlanmış formda olduğu belirlenmiştir. Çizelge 3' de TKA ve DFT/B3LYP/6-31++G(d,p) teori seviyesinde hesaplanan yanzincire ait dihedral açı değerleri karşılaştırıldığında birbirlerine oldukça yakın sonuçlar hesaplandığı bulunmuştur. Ancak TKA analizinde düzlemsel olarak kabul edilen DKP halkasının, DFT/B3LYP/6-31++G(d,p) teori seviyesi hesab1 sonucunda DKP halkas1 üzerindeki w1(N1-C39), w2(C19-N21), 1 1(N1-C3), 2 2(N21-C23), $\Psi 1(\mathrm{C} 3-\mathrm{C} 19)$ ve $\Psi 2(\mathrm{C} 23-\mathrm{C} 39)$ dihedral açıların sirasiyla $-6.9^{\circ},-5.3^{\circ}, 13.8^{\circ}, 12.3^{\circ},-7.3^{\circ}$ ve $-5.9^{\circ}$ hesaplanarak bu halkanın gaz fazında yapılan hesaplamalarda tamamen düzlemsel olmadığ 1 ancak düzlemsele yakın olduğu bulunmuştur (Şekil 5). Cyclo(His-Phe) dipeptidinin optimize geometrisi üzerine DFT/B3LYP/6-31++G(d,p) teori seviyesinde yapılan hesaplamalarda bu dihedral açılar sırasıyla $-4.31^{\circ},-9.86^{\circ}, 12.40^{\circ}, 7.05^{\circ},-4.82^{\circ}$ ve $-0.11^{\circ}$ hesaplanmıştır (Celik ve ark., 2012). c[L-Pip-Gly] üzerine yapılan optimize geometri hesabında bu açılar sırasıyla $-3.25^{\circ},-1.1^{\circ}, 5^{\circ}, 7.1^{\circ},-2.8^{\circ}$ ve $-4.7^{\circ}$ hesaplanmıştır (Budesinsky ve ark., 2017).

Sonuçlar, daha kısa zamanda ve daha az kapsamlı bilgisayar olanakları ile hesap yapılmasına olanak sağladığı için TKA' nin bir ilk yaklaşıklık olarak kullanılabileceğini göstermiştir. Ayrıca TKA sonuçları üzerinden yapılan DFT hesaplamalarında, en uygun ilk giriş verisi kullanıldığı için daha kısa zamanda sonuç alınabilmektedir. 


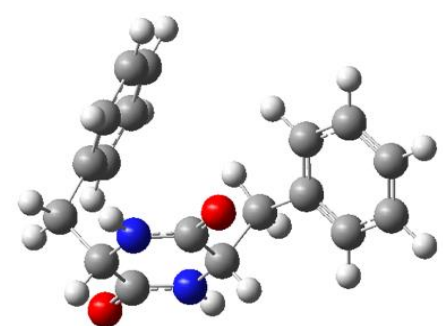

(II)

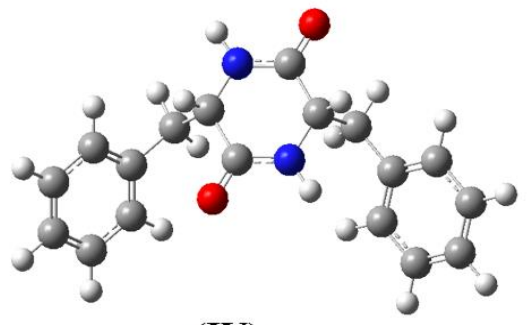

(IV)

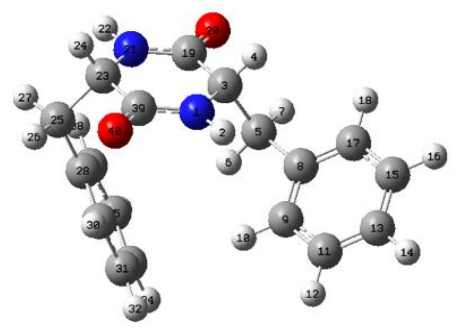

(I)
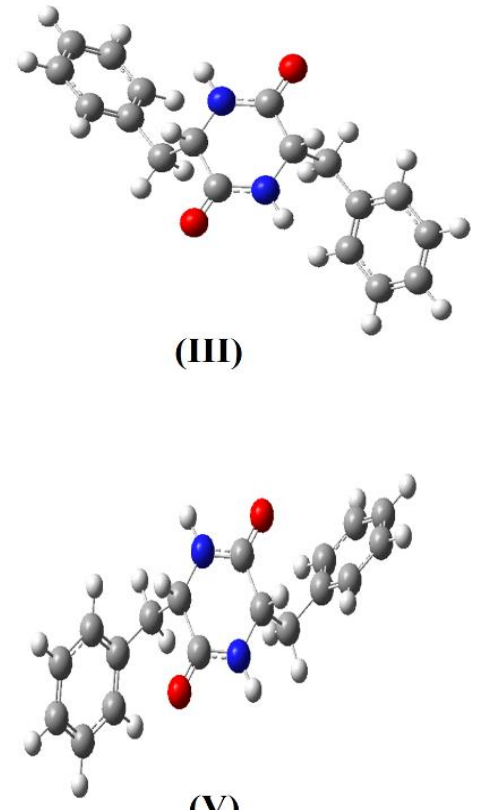

(V)

Şekil 1. Cyclo(Phe-Phe) dipeptidinin konformasyon analizi sonrasında elde edilen en düşük enerjili beş konformasyon.

Çizelge 1. Cyclo(Phe-Phe) en düşük enerjili beş konformasyonuna ait $\chi 11, \chi 12, \chi^{21}$ ve $\chi^{22}$ dihedral açıları $\left(^{\circ}\right)$

\begin{tabular}{|c|c|c|c|c|c|c|c|}
\hline Konformer & $\begin{array}{l}E_{\text {bağl }} \\
(\mathrm{kcal} / \mathrm{mol})\end{array}$ & $\begin{array}{l}\mathrm{E}_{\text {toplam }} \\
(\mathrm{kcal} / \mathrm{mol})\end{array}$ & & $\chi 11$ & $\chi 12$ & $\chi^{21}$ & $\chi 22$ \\
\hline \multirow[t]{2}{*}{ (I) } & 0 & -6.56 & GİRIŞ & -60.0 & 90.0 & 60.0 & 90.0 \\
\hline & & & ÇIKIŞ & -53.6 & 97.5 & 62.3 & 91.9 \\
\hline \multirow[t]{2}{*}{ (II) } & 1.79 & -4.77 & GİRIŞ & 180.0 & 90.0 & 60.0 & 90.0 \\
\hline & & & ÇIKIŞ & 195.8 & 65.5 & 61.6 & 93.2 \\
\hline \multirow[t]{2}{*}{ (III) } & 2.57 & -3.99 & GİRİŞ & -60.0 & 90.0 & -60.0 & 90.0 \\
\hline & & & ÇIKIŞ & -57.0 & 99.4 & -57.0 & 99.4 \\
\hline \multirow[t]{2}{*}{ (IV) } & 4.11 & -2.45 & GİRİŞ & -60.0 & 90.0 & 180.0 & 90.0 \\
\hline & & & ÇIKIŞ & -56.5 & 96.2 & 197.6 & 65.5 \\
\hline \multirow[t]{2}{*}{ (V) } & 5.66 & -0.90 & GİRİŞ & 180.0 & 90.0 & 180.0 & 90.0 \\
\hline & & & ÇIKIŞ & 198.0 & 63.9 & 198.0 & 63.9 \\
\hline
\end{tabular}

Çizelge 2. Cyclo(Phe-Phe) dipeptidinin konformerlerine ait toplam enerji ve van der Walls, elektrostatik, torsiyon enerji katk1ları $(\mathrm{kcal} / \mathrm{mol})$

\begin{tabular}{llllll}
\hline Konformer & $\mathrm{E}_{\text {bağıl }}$ & $\mathrm{E}_{\text {toplam }}$ & $\mathrm{E}_{\text {van der Walls }}$ & $\mathrm{E}_{\text {elektrostatik }}$ & $\mathrm{E}_{\text {torsiyon }}$ \\
\hline (I) & 0 & -6.56 & -6.49 & -0.16 & 0.09 \\
(II) & 1.79 & -4.77 & -5.13 & -0.13 & 0.49 \\
(III) & 2.57 & -3.99 & -3.87 & -0.16 & 0.04 \\
(IV) & 4.11 & -2.45 & -2.94 & -0.13 & 0.62 \\
(V) & 5.66 & -0.90 & -2.03 & -0.10 & 1.24 \\
\hline
\end{tabular}


Çizelge 3. Cyclo(Phe-Phe) dipeptidinin $\chi 11, \chi 12, \chi 21$ ve $\chi 22$ dihedral açılarındaki ( ${ }^{\circ}$ ) değişim

\begin{tabular}{lllll}
\hline Cyclo(Phe-Phe) & $\chi 11$ & $\chi 12$ & $\chi 21$ & $\chi^{22}$ \\
\hline TKA & -53.6 & 97.5 & 62.3 & 91.9 \\
\hline DFT-B3LYP/6-31++G(d,p) & -62.1 & 98.5 & 66.0 & 91.3 \\
\hline
\end{tabular}

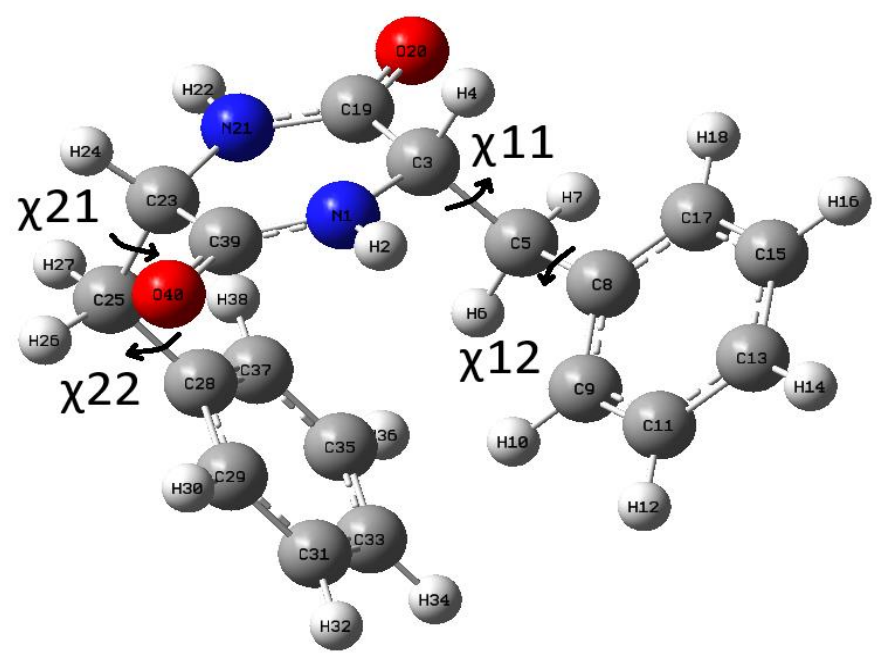

Şekil 2. Cyclo(Phe-Phe) dipeptidinin DFT/B3LYP/6-31++G(d,p) teori seviyesinde hesaplanan optimize geometrisi.

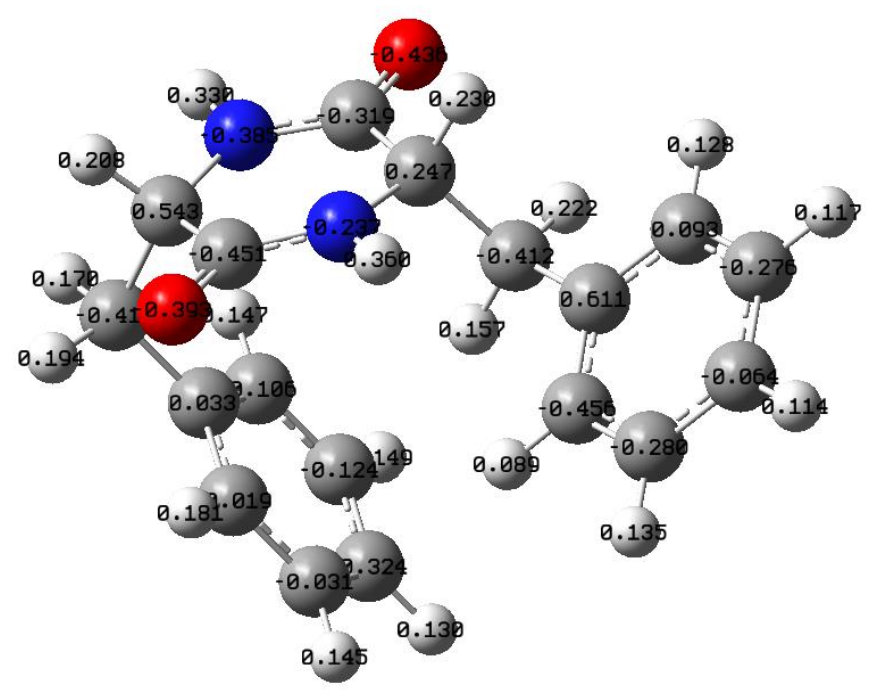

Şekil 3. DFT/B3LYP/6-31++G(d,p) teori seviyesinde belirlenen optimize geometriye ait yük dağılımı. 


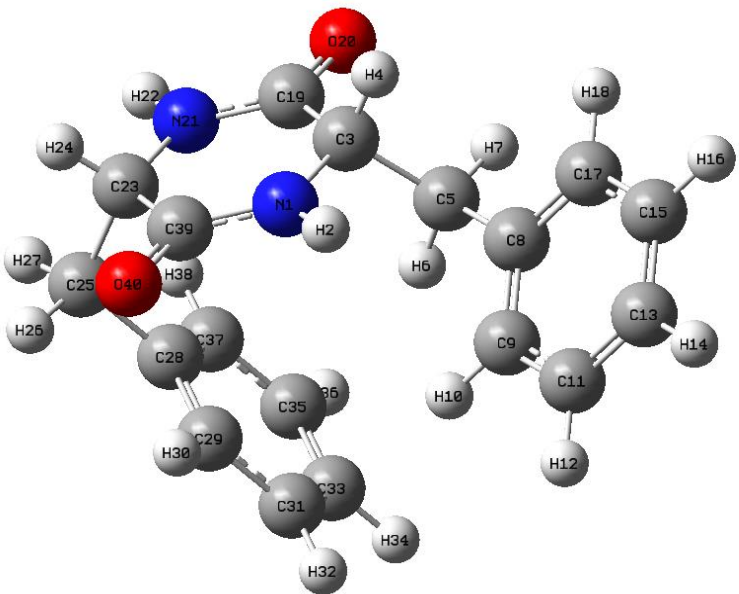

(a)

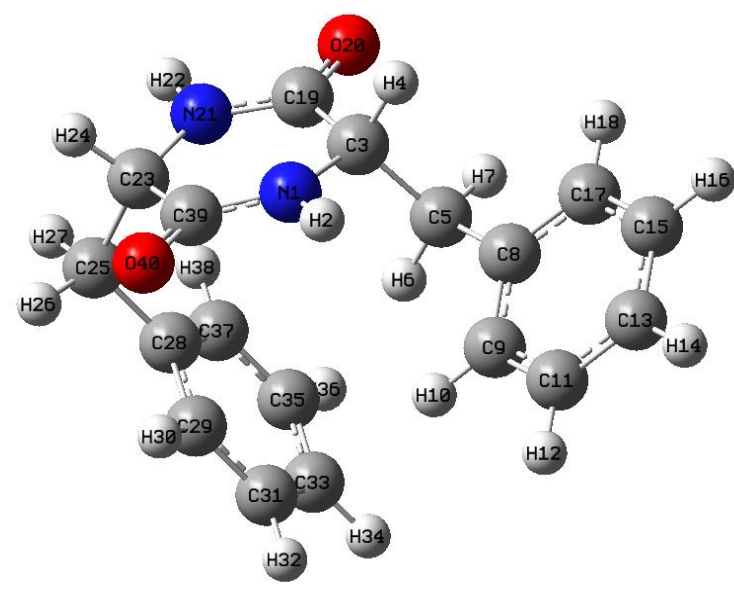

(b)

Şekil 4. Cyclo(Phe-Phe) dipeptidinin TKA (a) ve DFT/B3LYP/6-31++G(d,p) teori seviyesi (b) kullanılarak hesaplanan moleküler geometrisi.

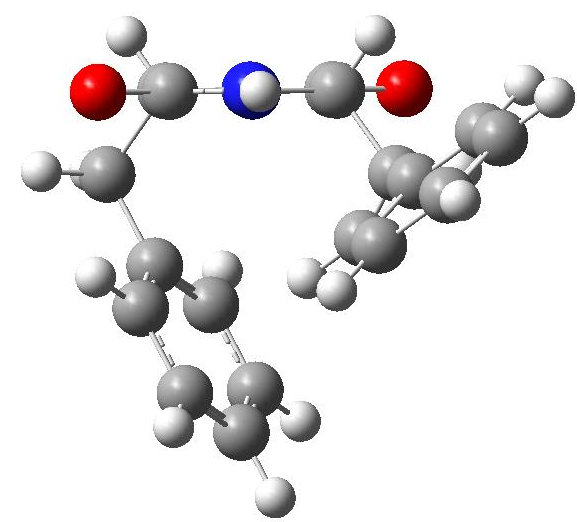

(a)

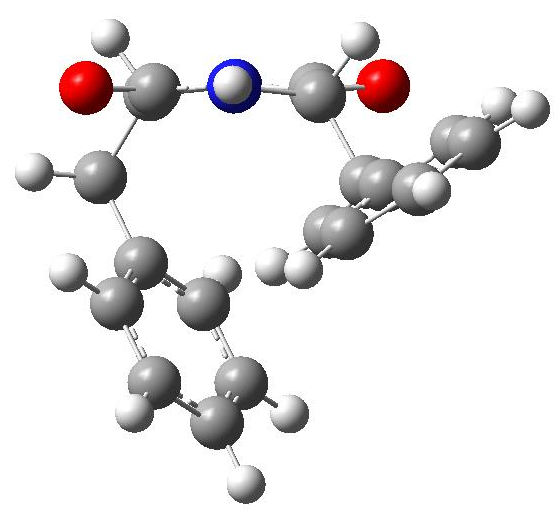

(b)

Şekil 5. Cyclo(Phe-Phe) dipeptidinin TKA (a) ve DFT/B3LYP/6-31++G(d,p) teori seviyesi (b) kullanılarak hesaplanan moleküler geometrisinde DKP halkasındaki değişim.

\section{Tartışma ve Sonuç}

$\mathrm{Bu}$ çalışmada, Cyclo(Phe-Phe) dipeptidinin konformasyon analizi ile bulunan en kararlı konformasyonu DFT/B3LYP/6-31++G(d,p) teori seviyesinde incelenmiştir. Şekil 4 ve Şekil 5' de TKA ve DFT/B3LYP/6-31++G(d,p) teori seviyesinde belirlenen moleküler geometriler karşılaştırmalı olarak verilmiştir. Optimizasyon sonucunda DKP halkasının düzlemsele yakın olduğu bulunmuştur. Cyclo(Gly-Gly) dipeptidi üzerine yapılan deneysel ve teorik çalışmalarda bu dipeptitin DKP halkasının da düzlemsel/düzlemsele yakın olduğu bulunmuştur (Mendam ve ark., 2009; Cheam \& Krimm, 1984). $\mathrm{Bu}$ çalışmada Cyclo(Phe-Phe) dipeptidinde fenilalanin amino asitine ait halka kısımlarının birbirlerine yaklaştı̆̆ 1 ve bu dipeptidin katlanmış formda olduğu saptanmıştır. DFT/B3LYP/6-31++G(d,p) teori seviyesinde yan zincire ait dihedral açılar sırasıyla $-62.1^{\circ}, 98.5^{\circ}, 66.0^{\circ}, 91.3^{\circ}$ hesaplanmıştır. Cyclo(TrpTrp) dipeptidi üzerine aynı teori seviyesinde yapılan hesaplamalarda yan zincire ait dihedral açılar $-65.9^{\circ},-90.3^{\circ}, 64.2^{\circ}$ ve $-86.4^{\circ}$ hesaplanmıştır (Celik ve ark., 2021). Cyclo(Phe-Phe) dipeptidinin en kararlı konformasyonlarının belirlenmesi, ilaç aktivitesinin anlaşılabilmesi bakımından önemlidir. Halka peptitlerin sentez sürecinde de bu belirlenen konformasyonlardan yararlanılabilinir. 


\section{Teşekkür}

Bu çalışma, İstanbul Üniversitesi Bilimsel Araştırma Projeleri Yürütücü Sekreterliğinin ÖNAP2423 numaralı projesi ile desteklenmiştir.

\section{Kaynakça}

Alieva, I. N., Mustafayeva, N. N., \& Gojayev, N. M. (2006). Conformational analysis of the N-terminal sequence Met1-Val60 of the tyrosine hydroxylase. Journal of Molecular Structure, 785(1-3), 76-84. doi: 10.1016/j.molstruc.2005.09.026

Becke, A. D. (1993). Density-functional thermochemistry, III. The role ofexact exchange.The Journal of chemical Physics, 98(7), 5648-5652. doi: 10.1063/1.464913

Borthwick, A. D., \& Da Costa, N. C. (2017). 2, 5-diketopiperazines in food and beverages: Taste and bioactivity. Critical reviews in food science and nutrition, 57(4), 718-742. doi: 10.1080/10408398.2014.911142

Budesinsky, M., Cisarova, I., Borremans, F., Martins, J. C., \& Pauwels, E. (2017). Solid-state structure of cyclic dipeptides: an X-ray and computational study of cis-and trans-diketopiperazines of Nmethyl-phenylalanine with the thia-pipecolic acids and thia-prolines. Acta Crystallographica Section B: Structural Science, Crystal Engineering and Materials, 73(6), 1179-1193. doi: 10.1107/S2052520617014731

Celik, S.,Ozel, A.E.,Kecel, S.,\&Akyuz, S. (2012). Structural and IR and Raman spectral analysis of cyclo(His-Phe) dipeptide. Vibrational Spectroscopy, 61, 54-65. doi:10.1016/j.vibspec.2012.01.014

Celik, S., \& Kecel-Gunduz, S. (2017). Conformational Analysis of Cyclo (Tyr-Cys) and Cyclo (PheCys) Dipeptides. Süleyman Demirel Üniversitesi Fen Bilimleri Enstitüsü Dergisi, 21(2), 306310.

Cheam, T. C., \& Krimm, S. (1984). Vibrational analysis of crystalline diketopiperazine-I. Raman and ir spectra. Spectrochimica Acta Part A: Molecular Spectroscopy, 40(6), 481-501.

Corey, R. B. (1938). The crystal structure of diketopiperazine. Journal of the American Chemical Society, 60(7), 1598-1604. doi: 10.1021/ja01274a023

Çelik, S., Akyüz, S., \& Özel, A.E. (2021). Antimikrobiyal ve Antikanser Aktiviteye Sahip Cyclo (TrpTrp) Dipeptidinin 3-Boyutlu Moleküler Yapısı. Yüzüncü Yll Üniversitesi Fen Bilimleri Enstitüsü Dergisi, 26(2), 80-87. doi: 10.53433/yyufbed.908710

Degeilh, R., \& Marsh, R. E. (1959). A refinement of the crystal structure of diketopiperazine (2, 5piperazinedione). Acta Crystallographica, 12(12), 1007-1014. doi: $10.1107 / \mathrm{S} 0365110 \mathrm{X} 59002845$

Demir, L., \& Godjaev, N. M. (2002). Conformational Analysis of Pol-Rfamide II (Glu ${ }^{1}-\operatorname{Trp}^{2}-\mathrm{Leu}^{3}$-Lys ${ }^{4}-$ Gly ${ }^{5}-\mathrm{Arg}^{6}-\mathrm{Phe}^{7}-\mathrm{NH}_{2}$ ) Heptapeptide. Turkish Journal of Chemistry, 26(6), 825-832.

Dorset, D. L. (2010). Direct methods and refinement in electron and X-ray crystallographydiketopiperazine revisited. Zeitschrift für Kristallographie International journal for structural, physical and chemical aspects of crystalline materials, 225(2-3), 86-93. doi: 10.1524/zkri.2010.1198

Falanga, A., Nigro, E., De Biasi, M. G., Daniele, A., Morelli, G., Galdiero, S., \& Scudiero, O. (2017). Cyclic peptides as novel therapeutic microbicides: Engineering of human defensin mimetics. Molecules, 22(7), 1217. doi: 10.3390/molecules22071217

Frisch, M. J., Trucks, G. W., Schlegel, H. B., Scuseria, G. E., Robb, M. A., Cheeseman, J. R., Montgomery Jr., J. A., Vreven, T., Kudin, K. N., Burant, J. C., Millam, J. M., Iyengar, S. S., Tomasi, J., Barone, V., Mennucci, B., Cossi, M., Scalmani, G., Rega, N., Petersson, G.A., Nakatsuji, H., Hada, M., Ehara, M., Toyota, K., Fukuda, R., Hasegawa, J., Ishida, M., Nakajima, T., Honda, Y., Kitao, O., Nakai, H., Klene, M., Li, X., Knox, J.E., Hratchian, H.P., Cross, J.B., Bakken, V., Adamo, C., Jaramillo, J., Gomperts, R., Stratmann, R.E., Yazyev, O., Austin, A.J., Cammi, R., Pomelli, C., Ochterski, J.W., Ayala, P.Y., Morokuma, K., Voth, G.A., Salvador, P., Dannenberg, J.J., Zakrzewski, V.G., Dapprich, S., Daniels, A. D., Strain, M. C., Farkas, O., 
Malick, D. K., Rabuck, A. D., Raghavachari, K., Foresman, J. B., Ortiz, J. V., Cui, Q., Baboul, A. G., Clifford, S., Cioslowski, J., Stefanov, B. B., Liu, G., Liashenko, A., Piskorz, P., Komaromi, I., Martin, R.L., Fox, D. J., Keith, T., Al-Laham, M. A., Peng, C. Y., Nanayakkara, A., Challacombe, M., Gill, P. M. W., Johnson, B., Chen, W., Wong, M. W., Gonzalez, C., \& Pople, J. A. (2004) .Gaussian 03, Revision C. 02, Gaussian, Inc., Wallingford CT.

Gao JP. 2013 Urethanes and ureas and processes. WO Patent no. 2013142969.

Gellerman, G., Hazan, E., Brider, T., Traube, T., Albeck, A., \& Shatzmiler, S. (2008). Facile synthesis of orthogonally protected optically pure keto-and diketopiperazine building blocks for combinatorial chemistry. International Journal of Peptide Research and Therapeutics, 14(2), 183-192. doi: 10.1007/s10989-008-9129-0

Graz, C. J. M., Grant, G. D., Brauns, S. C., Hunt, A., Jamie, H., \& Milne, P. J. (2000). Cyclic dipeptides in the induction of maturation for cancer therapy. Journal of pharmacy and pharmacology, 52(1), 75-82. doi: 10.1211/0022357001773535

Kaur, K., Kaur, S., \& Kapoor, V. K. (2020). Chemical synthesis and anti-inflammatory investigations of some cyclic peptide derivatives. Plant Archives, 20(2), 3531-3540.

Kelley, E. W., Norman, S. G., \& Scheerer, J. R. (2017). Synthesis of monoalkylidene diketopiperazines and application to the synthesis of barettin. Organic \& biomolecular chemistry, 15(40), 86348640. doi: 10.1039/C7OB02297B

Maksumov, I. S., Ismailova, L. I., \&Godjaev, N. M. (1983). The program for semiempirical calculation of conformations of the molecular complexes. J. Struc. Chem.(in Russian), 24, 147.

Mendham, A. P., Dines, T. J., Snowden, M. J., Chowdhry, B. Z., \& Withnall, R. (2009). Vibrational spectroscopy and DFT calculations of di-amino acid cyclic peptides. Part I: cyclo (Gly-Gly), cyclo (L-Ala-L-Ala) and cyclo (L-Ala-Gly) in the solid state and in aqueous solution. Journal of Raman Spectroscopy, 40(11), 1478-1497.

Mills, I., Cvitas, T., Homann, K., Kallay, N., \& Kuchitsu, K. (1988). IUPAC-IUB Quantity. Units and Symbols in Physical Chemistry. Oxford, UK: Blackwell Scientific Publications.

Popov, E. M. (1985). An approach to the problem of the structuro-functional organization of natural peptides. Molekuliarnaia biologiia ,19(4), 1107-1138.

Popov, E. M. (1979). Quantitative approach to conformations of proteins. International Journal of Quantum Chemistry, 16(4), 707-737. doi:10.1002/qua.560160403

Rahman, A. (2019). Studies in Natural Products Chemistry. Amsterdam: Elsevier.

Sun, M., Chen, X., Li, W., Lu, C., \& Shen, Y. (2017). New diketopiperazine derivatives with cytotoxicity from Nocardiopsis sp. YIM M13066. The Journal of antibiotics, 70(6), 795-797. doi: 10.1038/ja.2017.46

Tsuruoka, N., Beppu, Y., Koda, H., Doe, N., Watanabe, H., \& Abe, K. (2012). A DKP cyclo (L-Phe-LPhe) found in chicken essence is a dual inhibitor of the serotonin transporter and acetylcholinesterase. PLoS One, 7(11), e50824. doi: 10.1371/journal.pone.0050824

Walchshofer, N., Sarciron, M. E., Garnier, F., Delatour, P., Petavy, A. F., \& Paris, J. (1997). Anthelmintic activity of 3, 6-dibenzyl-2, 5-dioxopiperazine, cyclo (L-Phe-L-Phe). Amino Acids, 12(1), 41-47. doi: 10.1007/BF01373425

Zhang, D., \& Wang, W. (2018). A facile synthesis of cysteine-based diketopiperazine from thiolprotected precursor. Royal Society open science, 5(6), 180272. doi: 10.1098/rsos.180272 